\title{
Patterns of relationship regulation: German and French adolescents' perceptions with regard to their mothers
}

Isabelle Albert ${ }^{1}$

University of Luxembourg, Luxembourg

Gisela Trommsdorff ${ }^{2}$

University of Konstanz, Germany

Colette Sabatier ${ }^{3}$

Université Victor Segalen, Bordeaux, France

${ }^{1}$ Address correspondence to: Isabelle Albert, University of Luxembourg, Research Unit INSIDE, route de Diekirch, B.P.2, L-7250 Walferdange

Isabelle.Albert@uni.lu

${ }^{2}$ Gisela Trommsdorff, University of Konstanz, Faculty of Sciences, Department of Psychology, Developmental Psychology and Cross-Cultural Psychology, Post Box 14, D78457 Konstanz, Germany

Gisela.Trommsdorff@uni-konstanz.de

${ }^{3}$ Colette Sabatier, Université Victor Segalen, Bordeaux, 3 ter place de la Victoire, 33076 Bordeaux, France

Colette.Sabatier@u-bordeaux2.fr

This is an Author's Accepted Manuscript of an article published in FAMILY SCIENCE, Volume 2, Issue 1, pages 58-67, 2011 [copyright Taylor \& Francis], available online at: 


\section{Patterns of relationship regulation: German and French adolescents' perceptions with regard to their mothers}

Following a person-centered approach, the present study focuses on inter- and intracultural similarities and differences in patterns of relationship regulation by adolescents with regard to their mothers in a sample of 153 French and 154 German adolescents. Starting from theoretical assumptions of individuation in adolescence as the process of balancing autonomy and relatedness, a classification approach was applied providing four theoretically derived clusters of relationship regulation, namely "harmonious," "tense," "primary," and "secondary" relationship regulation patterns. Countries did not differ in numbers of adolescents in the "harmonious" and "tense" clusters. More patterns of "primary" relationship regulation were found between German adolescents and their mothers, whereas French families had a higher prevalence of "secondary" regulation patterns. Clusters were validated by maternal parenting (from adolescents' perspectives) and adolescents' optimism. Results on patterns of regulation are discussed in a theoretical framework of intrafamily processes of relationship regulation and implications for family functioning are addressed.

150 Words

Keywords: adolescence, autonomy, relatedness, France, Germany 
PATTERNS OF RELATIONSHIPS

Adolescence is a developmental period of significant transformations in social relationships (Steinberg \& Morris, 2001). The crucial task for families in the process of individuation is to renegotiate adolescents' different needs, such as constructing a distinct self and gaining more independence from parental authority (i.e., autonomy), or being attached to parents and receiving parental support (i.e., relatedness; Grotevant \& Cooper, 1985; Youniss \& Smollar, 1985). Earlier theories on individuation processes in adolescence have focused mostly on adolescents' separation and detachment from their parents (Blos, 1967). At present, it is widely acknowledged that individuation, starting in adolescence and extending to emerging adulthood, is a dual process including both adolescents' development of autonomy and the continuity of relatedness (Grotevant \& Cooper, 1985; Youniss \& Smollar, 1985; see also Arnett, 2000).

Adolescents may use different strategies to regulate their relationships to parents in line with their needs of autonomy and relatedness. The concept of relationship regulation underlines the active role of individuals in shaping their relational environment in accordance with their own needs and resources. Relationship regulation refers both to self-regulatory efforts of the individual and to attempts to change behaviors or cognitions of social partners (Lang, Wagner, \& Neyer, 2009). In the context of families both needs are co-regulated as part of the individuation process, depending on the importance ascribed to autonomy and relatedness in the family in accordance with underlying cultural factors such as value orientations, parenting, or agency beliefs (Rothbaum \& Trommsdorff, 2007).

Borrowing from theories on primary and secondary control (e.g., Rothbaum, Weisz, \& Snyder, 1982), we argue that adolescents may attempt to reconcile their needs of autonomy and relatedness within the specific family environment in which they are living either by a) trying to modify the given (relational) environment in line with their own goals, desires and expectations (primary control), or by b) adapting their cognitions and behaviours to the 


\section{PATTERNS OF RELATIONSHIPS}

existing relational realities (secondary control). Cross-cultural findings suggest that in socialisation contexts that foster autonomy and individuality, adolescents rather prefer primary control strategies, whereas in social-oriented contexts secondary control strategies are preferred (Trommsdorff \& Essau, 1998). Therefore, variations in "family cultures", characterized by specific family practices and interactions in line with underlying cultural models of family, may be found both between and within countries (cf. Manzi, Vignoles, Regalia, \& Scabini, 2006).

This assumption is in line with the culture-informed model of intergenerational relationships across the lifespan, which states that parent-adolescent relationships are embedded in the socioeconomic and cultural context (Trommsdorff, 2006).

The main aim of the present study is to identify patterns of regulation in the adolescent-mother relationship in Germany and France. Instead of studying single variables as main unit of analysis (variable-centered approach), we chose a person-centered approach that allows to identify configurations of variables referring to adolescents' individual patterns of relationship regulation by use of cluster analysis (see Bergman, 2001). In order to validate these patterns, we examined their links with perceived maternal parenting behavior and with aspects of adolescents' well-being.

Although we acknowledge the high relevance of fathers in socialisation, the present study focuses on the relationships between adolescents and their mothers. Earlier research suggests that fathers and mothers engage in important, but different roles in the relations to their children (Day \& Padilla-Walker, 2009). Whereas father-adolescent relationships can be characterised by more authority and fewer interactions, relations to mothers have been described as more connected and cooperative (Youniss \& Smollar, 1985). Also, the renegotiation of power tends to be accomplished earlier in relationships towards mothers 


\section{PATTERNS OF RELATIONSHIPS}

compared to fathers (e.g., Buhl, 2008), hence our particular interest to study individuation from mothers in adolescence as a critical phase.

The theoretical basis for the expected adolescent-mother relationship patterns of regulation and their associations with further variables is introduced in the following.

\section{Aspects of Adolescent-Parent Relationships Related to Individuation}

Which strategies do adolescents use to balance their needs in the process of individuation? First, adolescents regulate their individuation by the amount of personal thoughts and feelings they disclose to their mothers, indicating intimacy with mothers and emotional closeness (Buhrmester \& Furman, 1987). Several studies in Western countries have found rather open communication between adolescents and their parents, in particular with mothers, but self-disclosure is often confined to specific issues that change over time (Scabini, Marta, \& Lanz, 2006; see also Kerr, Stattin, \& Burk, 2010). Second, controversial discussions and disputes are an integral part of the individuation process as they may help to make the standpoints of different family members clear and distinguishable. Through the expression (and resolution) of conflicts, adolescents learn to establish their own views and ideas, and the family may renegotiate the roles and boundaries between family members (Allison \& Schultz, 2004; Perosa \& Perosa, 1993). Research has indicated that only a small portion of adolescentparent relationships involve major conflicts and can be described as problematic; the majority of arguments deal with rather minor disagreements over common daily issues (Steinberg \& Morris, 2001). The frequency of conflicts between adolescents and their mothers may be a proxy variable for autonomy strivings and self-assertion serving adolescents` individuality (see Grotevant \& Cooper, 1985). Third, perceived admiration might reflect relatedness to parents (Buhl, 2008; Youniss \& Smollar, 1985). Adolescents and young adults generally continue to rely heavily on their parents' (and especially their mother's) emotional support, advice, and approval, although friends and, later, also romantic partners assume increasingly 
PATTERNS OF RELATIONSHIPS

important roles (Buhl, 2008; Furman \& Buhrmester, 1992; Masche, 2008; Youniss \& Smollar, 1985). These three dimensions are part of the NRI (Network of Relationship Inventory; Furman \& Buhrmester, 1992) and were used in this study.

\section{Parenting and the Process of Individuation}

Adolescents' cognitive representations of their relationships with mothers are informed by their perceptions and interpretations of their mothers' parenting behaviors (such as promoting or hindering autonomy and relatedness; Grolnick, Gurland, DeCourcey, \& Jacob, 2002; Grusec \& Davidov, 2010). Hence, we try to validate patterns of relationships by examining their links with maternal parenting behavior as perceived by adolescents.

Within the framework of parental acceptance-rejection theory by Rohner (2004), a dimensional approach to parenting that has often been applied in cross-cultural research, a wide number of studies have demonstrated universally positive connotations of parental warmth with psychological and behavioral adjustment, whereas rejection has consistently negative effects on adolescents' developmental outcomes (Rohner, 2004; see also Grusec \& Davidov, 2010).

According to Rohner and Khaleque (2003), behavioural control refers to the demands and rules that parents formulate for their children, and to the extent to which they insist on compliance with their expectations (i.e., permissiveness vs. strictness). The control dimension of parenting has exhibited culturally specific correlates in several studies: in particular, in an individualist (in contrast to a collectivist) context, strict parental control can be perceived as restriction for adolescents' personal autonomy (e.g., Friedlmeier \& Trommsdorff, in press; Rohner \& Pettengill, 1985; Trommsdorff, 2006). A developmental task of parents with adolescents, therefore, is the adaptation of their parenting style to increased autonomy demands of their children, for instance by reducing their direct authority demands, 


\section{PATTERNS OF RELATIONSHIPS}

renegotiating rules and regulations with their children, and using more nonintrusive monitoring techniques (Kerr et al., 2010).

\section{Well-Being of Adolescents}

The importance of studying the link between types or patterns of adolescent-parent relationship quality and adolescents' psychological well-being and adjustment has been underlined by many authors (e.g., Caprara, Pastorelli, Regalia, Scabini, \& Bandura, 2005; Sabatier, Mayer, Friedlmeier, Lubiewska, \& Trommsdorff, in press; Schwarz et al., in press). In a cross-cultural study on adolescents with Dutch and ethnic backgrounds living in the Netherlands, Wissink and colleagues (2006) reported effects of parent-child relationship quality (as measured by the NRI dimensions of conflict, antagonism, and self-disclosure) on adolescents' self-esteem in all groups. Delaney (1996) provided similar evidence in a study on different types (or patterns) of relationships between adolescents and their parents. Adolescents in detached relationships reported greater anxiety, more depressive symptoms, and lower self-esteem than did those in either individuated or connected relationships with parents (see also Kruse \& Walper, 2008). Here, we focus on optimism, referring to generalized expectancies of positive outcomes, as a proxy measure for adolescents' wellbeing (Scheier, \& Carver, 1985; see also Hackney, \& Sanders, 2003), and analyze its relation to clusters of relationships. We expect that parent-adolescent interactions that promote autonomy while maintaining relatedness might foster adolescents' well-being, whereas negative outcomes are expected if these two needs are not balanced (cf., Allen, Hauser, Bell, \& O’Connor, 1994).

\section{Comparison Between Germany and France}

Only a few researchers have concentrated on differences in parent-child relations among European countries (e.g., Manzi et al., 2006), whereas most studies regarding differences in parent-child relationships among Western cultures have compared U.S. with 


\section{PATTERNS OF RELATIONSHIPS}

European samples (e.g., Laursen, Wilder, Noack, \& Williams, 2000; Suizzo, 2004). The question of whether the distribution of relationship regulation patterns is the same in Germany and France is justified based on earlier descriptions of culture specificities of German and French families with adolescents (e.g., Alsaker \& Flammer, 1999; Schleyer-Lindenmann, 2006). For instance, French parents tend to encourage their children to become independent, while also sharing the parenting goal of obedience (Sabatier \& Lannegrand-Willems, 2005; Suizzo, 2004). In contrast, German parents tend to promote independence and selfactualization in children, and these parenting goals might have replaced obedience and conformity expectations that were prevalent in Germany until the 1960s (Keller \& Lamm, 2005). French parents are reported to set limits and insist on compliance of their children (Claes, Lacourse, Bouchard, \& Perucchini, 2003), whereas German parent-adolescent relations are characterized by less authority (referring to the power distribution in the relationship) and more reciprocity (i.e., mutually negotiating the relationship) in comparison with parents in other Western countries such as the U.S. (Laursen et al., 2000). The reported findings converge with larger representative surveys (for a summary see, for instance, Gram, 1999) and indicate possible culture specificities.

\section{Aims of the Study}

The present study draws on an individuation-theoretical perspective, assuming that separation tendencies and autonomy strivings in adolescence do not preclude relatedness to parents, but may be simultaneous characteristics that stimulate relationships between adolescents and their parents (Youniss \& Smollar, 1985; see also Rothbaum \& Trommsdorff, 2007).

As our goal was to identify different patterns of relationship regulation, we used a person-centered approach applying cluster-analysis which allows us to simultaneously take 


\section{PATTERNS OF RELATIONSHIPS}

into account three core aspects of relationships (intimacy, conflict, perceived admiration), instead of addressing only isolated effects of each dimension (see Bergman, 2001). This is an advantage over variable-centered approaches. Therefore, family researchers increasingly use such pattern approaches (e.g., Delaney, 1996; Ferring, Michels, Boll, \& Filipp, 2009; Michels, Albert, \& Ferring, in press; Henry, Tolan, \& Gorman-Smith, 2005; Kruse \& Walper, 2008).

Families differ in the ways they regulate basic needs of autonomy and relatedness, so we expect to find different patterns of relationship regulation between adolescents and their mothers. Here, we follow the concept of relationship regulation as the reconciliation between different needs in parent-child relationships. This concept has also been applied with respect to the regulation of exchange processes, a typical task of balancing needs of closeness and reciprocity in adult child-parent relationships (Lang et al., 2009).

We further validate the clusters with (a) maternal parenting reported by adolescents and (b) adolescents' optimism. Apart from identifying and validating relationship patterns, we ask if different "family cultures" will be reflected by cross-cultural variation in the prevalences of patterns of relationships.

\section{Methods}

\section{Participants}

Participants were selected out of an original sample of 310 German and 197 French adolescents taking part in the larger cross-cultural "Value of Children and Intergenerational Relations" study that has been carried out in 16 countries in different parts of the world (Trommsdorff \& Nauck, 2010; see Mayer, Albert, Trommsdorff, \& Schwarz, 2005 for a detailed description of the German sample; Sabatier \& Lannegrand-Willems, 2005 for a detailed description of the French sample). German respondents came to equal parts from Chemnitz (a middle size town in East Germany), Konstanz (a middle size town in Southern 


\section{PATTERNS OF RELATIONSHIPS}

Germany), and Essen (a larger city in an urbanized industrialized area in North-Western

Germany). In France, respondents came to equal parts from Paris and its suburban areas, Bordeaux and surroundings, and smaller towns in rural areas all over France.

As the original French sample was smaller than the German sample, a selection was made in which both samples were similar with respect to mothers' educational level, adolescents' age, and gender distribution, resulting in a sample of 153 French adolescents and 154 German adolescents. Seventy percent of mothers had earned at least a high school diploma ("Bac" or "Abitur/Fachhochschulreife"). All German and most French adolescents were living in two-parent households $(10 \%$ of French adolescents were living with divorced, widowed or single mothers), and only one adolescent (in the French sample) was adopted. In most cases, the current partner of the mother was also the father of the target child, except for $16 \%$ of French and $6 \%$ of Germans families. All adolescents were attending school. The mean age of adolescents was 16 years $(M=15.73$ years, $S D=1.04$ years in Germany, and $M=$ 15.85 years, $S D=1.12$ years in France; Range for both: $13-18$ years). Forty-four percent of the German adolescents and $46 \%$ of the French adolescents were male.

\section{Measures}

Self-reports of adolescents were obtained with a standardized questionnaire written in either German or French, respectively. The questionnaire was originally developed in English as part of the larger cross-cultural project and translated then in the respective language versions by a team of bilingual psychologists. Back translation was used to ensure adequacy of the country specific questionnaire versions (Van de Vijver \& Leung, 1997).

Several measures that appraise family relations are available from previous studies. A convincing approach that allows researchers to measure relationship quality with specific relationship partners was provided by Furman and Buhrmester (1992). The Network of Relationship Inventory (NRI) concentrates on different relationship aspects to draw a 
PATTERNS OF RELATIONSHIPS

comprehensive picture of the quality of close relationships of children and adolescents toward different network partners over time. This questionnaire has proven useful in a range of studies in different cultures and languages (Furman \& Buhrmester, 2009). Specifically, it has been applied in several recent studies focusing on individuation processes from adolescence to adulthood (e.g., Buhl, 2008; Wissink, Dekovic, \& Meijer, 2006). Among the different dimensions of the NRI, we used intimacy, perceived admiration and conflict with mothers as these are relationship aspects that may be regulated by adolescents in order to balance their needs of relatedness and autonomy during the individuation process (Furman \& Buhrmester, 1992). Intimacy was measured with three items, conflict and felt admiration with two items each, all rated on a 5-point Likert scale ( 1 = never, 5 = always $)$.

The Parental Acceptance-Rejection Questionnaire with the Control Supplement (e.g., Rohner \& Khaleque, 2003) was applied to measure adolescents' perception of maternal parenting. The dimension of acceptance contained 10 items, the dimension of control (i.e. permissiveness vs. strictness) contained six items, and the dimension of rejection contained eight items, all rated on a 4-point Likert-scale $(1=$ almost never true, $4=$ almost always true $)$.

To measure adolescents' optimism, the Life-Orientation-Test by Scheier and Carver (1985) was applied using seven items that were rated on a 5-point Likert scale $(1=$ strongly disagree; 5 = strongly agree). Table 1 reports the scale properties. 
PATTERNS OF RELATIONSHIPS

\section{Results}

\section{Preliminary Analyses}

Item bias due to flaws in translation or participants' understanding concepts differently may distort results in cross-cultural studies (Van de Vijver \& Leung, 1997). Therefore, we checked measurement equivalence between both groups with respect to the three applied relationship dimensions, intimacy, conflict, and perceived admiration, in a three-factor model. Confirmatory factor analyses with AMOS 18 demonstrated that the most restrictive model indicating scalar invariance fit the data well $\left(\chi^{2} / d f=1.96, \mathrm{CFI}=.95, \mathrm{RMSEA}=.06\right)$ and did not differ significantly from the less restrictive model of metric invariance (parameters testing the scalar against the metric invariance model were $\chi^{2}=9.19, d f=7, p=.24$ ). This model constrained intercepts, factor loadings between indicators and constructs, and covariances between constructs to be equal in both cultural groups (see Davidov, Schmidt, \& Schwartz, 2008). As scalar invariance allows for mean comparison of the groups, it was thus possible to carry out cluster analyses for the full sample. Confirmatory factor analyses provided further evidence for metric equivalence of the three dimensions of perceived parenting and of the optimism scale in both national groups, indicating that the assumed factorial structure for these indicators holds in both samples.

\section{Main Analyses}

To describe types of adolescent-mother relationships, we carried out a hierarchical cluster analysis for the three relationship scales (standardized for the full sample) using the Ward method and employing squared Euclidian distance as proximity measure. According to the agglomeration coefficients, a four- or five-cluster solution was appropriate; the more parsimonious four-cluster solution was chosen. $K$-means cluster analyses were applied to improve the classification of adolescents into the four-relationship cluster. The final cluster 


\section{PATTERNS OF RELATIONSHIPS}

solution was found in three iterations (see Figure 1 and Table 2). In order to check for adequacy of the clusters in both countries, we also carried out the same cluster analyses separately for German and French adolescents. For both countries, a four-cluster solution was compatible with the data.

Adolescents in the first cluster (31\% of all adolescents) reported below-average intimacy and conflict, and perceived admiration in their relationships with their mothers around the midpoint of the scale. This cluster was labeled secondary regulation drawing on theories of primary and secondary control (e.g., Rothbaum \& Wang, 2010). As said before, secondary control refers to the adaptation of the self to the (relational) environment-i.e., accommodating to the given relationship.

The second cluster labeled tense regulation (20.9\% of adolescents) was characterized by frequent conflicts, but lower-than-average intimacy and admiration. The third cluster labeled primary regulation (29.7\% of adolescents) contained amounts of intimacy, conflict, and admiration that corresponded to the respective sample means. According to the theory of relationship regulation, primary control refers to the attempt of the individual to modify the (relational) environment-for instance, by actively negotiating the relationship. The last cluster labeled harmonious regulation (18.3\% of adolescents) was characterized by high intimacy and admiration and low levels of conflict.

The clusters did not differ in age of adolescents, $F(3,305)=1.27$, ns. A small marginal gender effect was found (Cramer's $V=.15, p<.10$ ): more boys than girls belonged to the "secondary" cluster ( $36.2 \%$ of all boys vs. $26.8 \%$ of all girls), whereas girls were overrepresented in the "tense" cluster ( $25.6 \%$ of all girls vs. $15.2 \%$ of all boys). This gender distribution in the clusters is consistent with earlier research reporting that girls experience both more intimate relationships with their mothers and more conflicts than do boys (e.g., Allison \& Schultz, 2004; Furman \& Buhrmester, 1992). 
PATTERNS OF RELATIONSHIPS

Clusters differ across cultures (Cramer's $V=.16, p<.05$ ): more than a third of German adolescents, but only a fourth of French adolescents belonged to the "primary" cluster. The reverse pattern was found for the "secondary" cluster. However, German and French adolescents were distributed equally to the "tense" and "harmonious" clusters (see Table 3).

In order to validate the clusters, we first compared the four groups regarding different parenting dimensions, controlling for possible country effects (see Table 4). Clusters and countries differed with respect to perceived acceptance; no interaction effect was found. We carried out pairwise comparisons (Tukey's HSD) of clusters and found that all four clusters differed from each other: highest maternal acceptance was perceived by adolescents in the "harmonious" cluster, followed by "primary," "secondary," and finally "tense” clusters. Further, French adolescents rated their perceived acceptance somewhat lower than did German adolescents. Concerning perceived rejection, again two main effects (cluster and country) were found. Pairwise comparisons (Tukey's HSD) indicated that adolescents in the "tense" cluster perceived higher rejection than did adolescents in all other clusters, whereas the remaining three clusters did not differ from each other. Also, French adolescents as a group rated perceived rejection slightly higher than did Germans. Main effects for cluster and country were also found regarding perceived maternal control. However, the pairwise comparisons did not indicate any significant differences between clusters. French adolescents rated maternal control generally higher than did German participants.

Finally, comparing optimism in the different groups showed both a cluster and a country main effect. Pairwise comparisons indicated that "tense" adolescents were least optimistic, and "harmonious" adolescents were most optimistic. "Secondary" and "primary" adolescents were in between: "secondary" adolescents were significantly less optimistic than "harmonious" adolescents and "primary" adolescents were significantly more optimistic than 
PATTERNS OF RELATIONSHIPS

"tense" adolescents. Also, German adolescents were found to be more optimistic than French adolescents (a similar result was reported by Grob, Stetsenko, Sabatier, Botcheva, \& Macek, 1999).

\section{Discussion}

The present study draws on the observation that adolescence cannot be described in a uniform way and that adolescents are not a homogeneous group. Assuming that different strategies may be used to balance needs of autonomy and relatedness, the main aim was to find out which patterns of regulation can be observed in adolescent-mother relationships in Germany and France. As expected, the person-oriented approach was useful for providing a deeper insight into the variety of parent-child relationships in adolescence both between and within countries by demonstrating several patterns of relationship regulation (see also Bergman, 2001).

Four different clusters were identified describing patterns of "secondary," "tense," "primary," and "harmonious" relationship regulation in German and French families with adolescents. The first pattern indicates the often-cited tendency of adolescents to separate and withdraw from their family as part of their search for identity. This cluster was labeled "secondary," drawing on concepts of primary and secondary control (e.g., Rothbaum \& Trommsdorff, 2007; Rothbaum \& Wang, 2010; Trommsdorff \& Essau, 1998). Accordingly, adolescents who use a "secondary" regulation strategy accommodate to the existing maternal relationship. They create individuality by communicating less openly with their mothers, keeping their personal matters to themselves without defending their autonomy by open conflicts. This restricted communication does not, however, preclude their feelings of being accepted and valued by their mothers (see also Youniss \& Smollar, 1985). These adolescents seem to separate themselves from their mothers without detaching. This conforms to several 


\section{PATTERNS OF RELATIONSHIPS}

studies that have clearly distinguished separation and detachment as two distinct aspects of autonomy (Beyers, Goossens, Vansant, \& Moors, 2003; Lamborn \& Groh, 2009).

The "tense" pattern corresponded to earlier descriptions of adolescence as a rather problematic phase, with communication between adolescents and mothers being disturbed by conflicts. These adolescents seem to detach from their mothers in their struggle for autonomy; the expression of their own opinions may not find approval with their mothers, as reflected by the relatively high frequency of conflicts and low levels of both intimacy and perceived admiration.

In the "primary" regulation cluster, conflicts occur as a typical part of relationship renegotiation in adolescence, coexisting with positive aspects of the relationship. In the sense of primary control strategies, these adolescents attempt to influence the existing maternal relationship (Trommsdorff \& Essau, 1998). Adolescents in this cluster communicate openly with their mothers, expressing their own viewpoints even if these differ from their mothers' ideas, without fear of losing their mothers' approval; conflicts may serve to clarify boundaries within the family. These results underline that the frequency of conflicts per se cannot be taken as an indicator of a negative relationship quality, but has to be seen in the context of other relationship aspects (Cicognani \& Zani, 2009); hence, the advantage of the pattern approach.

The "harmonious" cluster, described highly coherent parent-child relationships in which high self-disclosure and appreciation was accompanied by an absence of conflicts. These adolescents treat their mothers as confidants and do not seem to struggle for autonomy via conflicts. On the basis of our data we cannot conclude, however, whether these adolescents show autonomy in their actual behavior.

Relationships in both countries could be described by similar patterns, which only differed in part with respect to frequency. Both "tense" and "harmonious" relationships 


\section{PATTERNS OF RELATIONSHIPS}

occurred equally frequently in both countries. However, the clusters that refer to two different styles of developing autonomy while preserving relatedness, namely "primary" (relationship renegotiation by self-assertion) versus "secondary" (setting boundaries by decreased communication) styles, were distributed differently across the two countries. The different adherence to the "primary" and "secondary" regulation clusters point to cultural specificities in German and French "family cultures" as described in earlier studies (Claes et al., 2003; Keller \& Lamm, 2005; Laursen et al., 2000). For instance, French mothers tend to encourage their children to become independent, but they also emphasise goals of obedience and social integration (e.g., Sabatier \& Lannegrand-Willems, 2005; Suizzo, 2004), whereas German mothers rather promote independence and self-actualization in their children (e.g., Keller \& Lamm, 2005). Drawing on earlier findings in individualist and collectivistic contexts regarding differences in the development of primary and secondary control, differences in parenting goals may account for the development of different regulation patterns. Indeed, earlier studies reported that primary control is fostered in contexts that emphasise the individual self, whereas secondary control has a higher prevalence in contexts favouring conformity and group-orientation (Rothbaum \& Wang, 2010; Trommsdorff, \& Essau, 1998; Trommsdorff, in press). The present results underline the importance of cross-cultural comparisons of adolescent-parent relationships among Western countries (cf. Buhl, 2008).

The associations between perceived acceptance-rejection and the relationship clusters were similar in both countries. The results support the assumption of acceptance contributing to positive relationship quality and rejection contributing to negative relationship quality. The results also serve as validation criterion for the relationship clusters in line with Rohner (2004). The "tense" cluster is notable because adolescents in this cluster had the lowest perceived maternal acceptance and the highest feeling of rejection, while the reverse was true for the "harmonious" cluster. Although a warm and responsive parenting style forms the basis 


\section{PATTERNS OF RELATIONSHIPS}

for a non-tense relationship (cf. Rohner, 2004), the remaining "primary" and "secondary" clusters were less clearly distinguishable, demonstrating that the exact form of relation cannot be predicted by acceptance-rejection alone. In this regard, Grusec and Davidov (2010) recently argued that parental warmth is too wide a category - the functionality of warmth and acceptance depends on the specific domain where it is applied.

Maternal control did not predict adherence to particular clusters, again suggesting different effects of this parenting dimension depending on context (e.g., Grolnick et al., 2002; Trommsdorff \& Friedlmeier, 2010). The maternal control variable was generally more important in France than in Germany indicating higher acceptance of parental authority in French than in German families (cf. Claes et al., 2003; Keller \& Lamm, 2005).

As expected, low-rated optimism as indicator of well-being of adolescents was related to the "tense" cluster in both countries, whereas all other groups fared rather well regarding optimism. This indicates that conflicts are highly unfavorable for adolescents' well-being if they co-occur with detachment from mothers. However, conflicts or separation of adolescents may not necessarily induce negative outcomes as long as they are accompanied by continued direct or indirect forms of closeness to mothers (Perosa \& Perosa, 1993).

\section{Caveats}

The lack of age differences between clusters may be due to the rather small age range of adolescents in the present study. Also, there may be individual differences in adolescents' developmental transitions regarding different speed and time points. It would be desirable to examine in a longitudinal design how relationship patterns evolve over time and if oscillation between clusters can be found (cf. Ferring et al., 2009). For instance, depending on the stage in the individuation process, phases of more frequent conflicts may alternate with more harmonious phases. Adolescents in the harmonious cluster may have acted out and resolved 
PATTERNS OF RELATIONSHIPS

conflicts in earlier phases, they may enter a more troubled phase at a later time point, or avoid conflicts with mothers over the whole course of adolescence (Masche, 2008).

The present study was limited to the adolescent-mother relation as crucial for individuation in adolescence. As fathers and mothers may have distinct roles in socialization (see e.g., Day \& Padilla-Walker, 2009), future research should also draw a closer look at adolescents' individuation from fathers. Apart from the study of dyadic relationships, the study of the whole family climate would possibly provide further insights (see Roest, Dubas, \& Gerris, 2009).

The present sample was not nationally representative for German and French families, but consisted of families with a moderate-to-high educational status. Although it would be desirable to compare representative samples in both countries, this is rarely realized in crosscultural studies because of the high costs that generating nationally representative samples in more than one country would involve (see Manzi et al., 2006). Here, our main concern was to ensure comparability of the samples by keeping the main socioeconomic variables similar in both samples, namely educational status of the mothers, gender proportions, and adolescents' age. Also, we included different population groups by selecting samples from three different regions in each country.

\section{Conclusions}

The identified clusters -secondary control, tense, primary control, and harmoniousgive a comprehensive picture of the range of theoretically relevant relationship patterns in adolescence in two Western countries. Relationship regulation differs between families and between cultures depending on how much importance families attach to autonomy and relatedness of their members, and there are different ways to regulate the balance between both needs. 


\section{PATTERNS OF RELATIONSHIPS}

The present research has also implications for intervention: parents may find it helpful to learn that adolescents apply different strategies to balance autonomy and relatedness in the process of individuation, and this may enable them to better understand and respond more appropriately to adolescents' specific needs.

The strength of the present study is the person-centered approach which allows studying the combination of different relationship aspects. This is especially important for investigating the role of conflicts, the meaning of which depends on its combination with other relationship aspects.

4963 Words (6676 with references and acknowledgements) 
PATTERNS OF RELATIONSHIPS

Acknowledgements

This research was supported by a grant from the Deutsche Forschungsgemeinschaft (TR 169/9-1-3) to the second author. The project is part of the study "Value of Children and Intergenerational Relations" (Principal Investigators: Gisela Trommsdorff, University of Konstanz, Germany, and Bernhard Nauck, Technical University of Chemnitz, Germany). Data of the German sample were collected under the guidance of Gisela Trommsdorff and Bernhard Nauck. Data for the French sample were collected under the guidance of Colette Sabatier.

The manuscript is partly based on the dissertation thesis of the first author.

We thank Holly Bunje for her editorial help and we thank two anonymous reviewers for their helpful comments on an earlier version of the manuscript. 
PATTERNS OF RELATIONSHIPS

\section{References}

Allen, J. P., Hauser, S. T., Bell, K. L., \& O’Connor, T. G. (1994). Longitudinal assessment of autonomy and relatedness in adolescent-family interactions as predictors of adolescent ego development and self-esteem. Child Development, 65, 179-194.

Allison, B. N., \& Schultz, J. B. (2004). Parent-adolescent conflict in early adolescence. Adolescence, 39, 101-119.

Alsaker, F. D., \& Flammer, A. (1999) (Eds.). The adolescent experience. European and American adolescents in the 1990s. Mahwah, NJ: Erlbaum.

Arnett, J. J. (2000). Emerging adulthood. A theory of development from the late teens through the twenties. American Psychologist, 55, 469-480.

Bergman, L. R. (2001). A person approach in research on adolescence: Some methodological challenges. Journal of Adolescent Research, 16, $28-53$.

Beyers, W., Goossens, L., Vansant, I., \& Moors, E. (2003). A structural model of autonomy in middle and late adolescence: Connectedness, separation, detachment, and agency. Journal of Youth and Adolescence, 32, 351-365.

Blos, P. (1967). The second individuation process of adolescence. Psychoanalytic Study of the Child, 22, 162-186.

Buhl, H. M. (2008). Development of a model describing individuated adult child-parent relationships. International Journal of Behavioral Development, 32, 381-389.

Buhrmester, D., \& Furman, W. (1987). The development of companionship and intimacy. Child Development, 85, 1101-1113. 


\section{PATTERNS OF RELATIONSHIPS}

Caprara, G. V., Pastorelli, C., Regalia, C., Scabini, E., \& Bandura, A. (2005). Impact of adolescents' filial self-efficacy on quality of family functioning and satisfaction. Journal of Research on Adolescence, 15, 71-97.

Cicognani, E., \& Zani, B. (2009). Conflict styles and outcomes in families with adolescent children. Social Development, 19, 427-436.

Claes, M., Lacourse, E., Bouchard, C., \& Perucchini, P. (2003). Parental practices in late adolescence, a comparison of three countries: Canada, France and Italy. Journal of Adolescence, 26, 387-399.

Day, R. D., \& Padilla-Walker, L. M. (2009). Mother and father connectedness and involvement during early adolescence. Journal of Family Psychology, 23, 900-904.

Davidov, E., Schmidt, P., \& Schwartz, S. H. (2008). Bringing values back in: The adequacy of the European Social Survey to measure values in 20 countries. Public Opinion Quarterly, 72, 420-445.

Delaney, M. E. (1996). Across the transition to adolescence. Qualities of parent/adolescent relationships and adjustment. The Journal of Early Adolescence, 16, 274-300.

Ferring, D., Michels, T., Boll, T., \& Filipp, S.-H. (2009). Relationship quality with ageing parents: On solidarity, conflicts, and ambivalence. European Journal of Ageing, 6, 253265.

Furman, W., \& Buhrmester, D. (1992). Age and sex differences in perceptions of networks of personal relationships. Child Development, 63, 103-115. 


\section{PATTERNS OF RELATIONSHIPS}

Furman, W., \& Buhrmester, D. (2009). The Network of Relationships Inventory: Behavioral Systems Version. International Journal of Behavioral Development, 33, 470-478.

Gram, M. (1999). National socialisation and education: A comparison of ideals for the upbringing of children and the school systems in France, Germany and the Netherlands". Discussion Papers, SPIRIT. Aalborg University: Center for International Studies.

Grob, A., Stetsenko A., Sabatier, C., Botcheva, L., \& Macek, P. (1999). A cross-national model of subjective well-being in adolescence. In F. D. Alsaker \& A. Flammer (Eds.), The adolescent experience: European and American adolescents in the 1990s (pp. 115-130). Hillsdale, NJ: Erlbaum.

Grolnick, W. S., Gurland, S. T., DeCourcey, W., \& Jacob, K. (2002). Antecedents and consequences of mothers' autonomy support: An experimental investigation. Developmental Psychology, 38, 143-155.

Grotevant, H. D., \& Cooper, C. R. (1985). Patterns of interaction in family relationships and the development of identity exploration in adolescence. Child Development, 56, 415428.

Grusec, J. E., \& Davidov, M. (2010). Integrating different perspectives on socialization theory and research: a domain-specific approach. Child Development, 81, 687-709.

Hackney, C. H., \& Sanders, G. S. (2003). Religiosity and mental health: A meta-analysis of recent studies. Journal for the Scientific Study of Religion, 42(1), 43-55.

Henry, D. B., Tolan, P. H., \& Gorman-Smith, D. (2005). Clustering methods in family psychology research. Journal of Family Psychology, 19, 121-132. 


\section{PATTERNS OF RELATIONSHIPS}

Keller, H., \& Lamm, B. (2005). Parenting as the expression of sociohistorical time: The case of German individualisation. International Journal of Behavioral Development, 29, $238-246$.

Kerr, M., Stattin, H., \& Burk, W. J. (2010). A reinterpretation of parental monitoring in longitudinal perspective. Journal of Research on Adolescence, 20, 39-64.

Kruse, J., \& Walper, S. (2008). Types of individuation in relation to parents: Predictors and outcomes. International Journal of Behavioral Development, 32, 590-400.

Lamborn, S. D., \& Groh, K. (2009). A four-part model of autonomy during emerging adulthood: Associations with adjustment. International Journal of Behavioral Development, 33, 393-401.

Lang, F. R., Wagner, J., \& Neyer, F. J. (2009). Interpersonal functioning across the lifespan: Two principles of relationship regulation. Advances in life course research, 14, 40-51.

Laursen, B., Wilder, D., Noack, P., \& Williams, V. (2000). Adolescent perceptions of reciprocity, authority, and closeness in relationships with mothers, fathers, and friends. International Journal of Behavioral Development, 24, 464-471.

Manzi, C., Vignoles, V. L., Regalia, C., \& Scabini, E. (2006). Cohesion and enmeshment revisited: Differentiation, identity, and well-being in two European cultures. Journal of Marriage and the Family, 68, 673-689.

Masche, J. G. (2008). Reciprocal influences between developmental transitions and parentchild relationships in young adulthood. International Journal of Behavioral Development, 32, 401-411. 
PATTERNS OF RELATIONSHIPS

Mayer, B., Albert, I., Trommsdorff, G., \& Schwarz, B. (2005). Value of children in Germany: Dimensions, comparison of generations, and relevance for parenting. In G.

Trommsdorff \& B. Nauck (Eds.), The value of children in cross-cultural perspective. Case studies from eight societies (pp. 43-65). Lengerich, Germany: Pabst Science.

Michels, T., Albert, I., \& Ferring, D. (in press). Emotional relations with grandparents and received support: The adolescent view. Journal of Intergenerational Relationships, 9 (3).

Perosa, S., \& Perosa, L. (1993). Relationships among Minuchin’s Structural Family Model, identity achievement, and coping style. Journal of Counseling Psychology, 40, 479489.

Roest, A. M. C., Dubas, J. S., \& Gerris, J. R. M. (2009). Value transmissions between fathers, mothers, and adolescent and emerging adult children: The role of the family climate. Journal of Family Psychology, 23, 146-155.

Rohner, R. P. (2004). The parental "acceptance-rejection syndrome": Universal correlates of perceived rejection. The American Psychologist, 59, 830-840.

Rohner, R. P. \& Khaleque, A. (2003). Reliability and validity of the parental control scale: A meta-analysis of cross-cultural and intracultural studies. Journal of Cross-Cultural Psychology, 34, 643-649.

Rohner, R. P., \& Pettengill, S. M. (1985). Perceived parental acceptance-rejection and parental control among Korean adolescents. Child Development, 56, 524-528.

Rothbaum, F., \& Trommsdorff, G. (2007). Do roots and wings complement or oppose one another: The socialization of relatedness and autonomy in cultural context. In J. 


\section{PATTERNS OF RELATIONSHIPS}

Grusec \& P. Hastings (Eds.), Handbook of socialization, 2nd edition, (pp. 461-489). New York: Guilford Press.

Rothbaum, F., Weisz, J., \& Snyder, S. (1982). Changing the world and changing the self: A two-process model of perceived control. Journal of Personality and Social Psychology, 42, 5-37.

Rothbaum, F. \& Wang, Y.Z. (2010). Fostering the child's malleable views of the self and the world: Caregiving practices in East Asian and European-American communities. In H.J. Kornadt \& B. Mayer (Eds.), Psychologie, Kultur, Gesellschaft (pp. 101-120). Wiesbaden: VS Verlag für Sozialwissenschaften.

Sabatier, C., \& Lannegrand-Willems, L. (2005). Transmission of family values and attachment: A French three-generation study. Applied Psychology: An International Review, 54, 378-395.

Sabatier, C., Mayer, B., Friedlmeier, M., Lubiewska, K., \& Trommsdorff, G. (in press). Religiosity, family orientation, and life satisfaction of adolescents in four countries. Journal of Cross-Cultural Psychology.

Scabini, E., Marta, E., \& Lanz, M. (2006). The transition to adulthood and family relations. New York: Psychology Press.

Scheier, M. F., \& Carver, C. S. (1985). Optimism, coping, and health: Assessment and implications of generalized outcome expectancies. Health Psychology, 4, 219-247.

Schleyer-Lindenmann, A. (2006). Developmental tasks of adolescents of native or foreign origin in France and Germany. Journal of Cross-Cultural Psychology, 37, 85-99. 


\section{PATTERNS OF RELATIONSHIPS}

Schwarz, B., Mayer, B., Trommsdorff, G., Ben-Arieh, A., Friedlmeier, M., Lubiewska, K., Mishra, R. C., \& Peltzer, K. (in press). Does the importance of parent and peer relationships for adolescents' life satisfaction vary across cultures? Journal of Early Adolescence.

Steinberg, L., \& Morris, A. S. (2001). Adolescent development. Annual Review of Psychology, 52, 83-110.

Suizzo, M.-A. (2004). French and American mothers' childrearing beliefs: Stimulating, responding, and long-term goals. Journal of Cross-Cultural Psychology, 35, 606-626.

Trommsdorff, G. (2006). Parent-child relations over the life-span. A cross-cultural perspective. In K. H. Rubin \& O. B. Chung (Eds.), Parenting beliefs, behaviors, and parent-child relations. A cross-cultural perspective. (pp. 143-183). New York: Psychology Press.

Trommsdorff, G. (in press). Development of agentic regulation in cultural context: The role of self- and world views. Child Development Perspectives.

Trommsdorff, G., \& Essau, C. A. (1998). Japanese and German adolescents’ control orientation: A cross-cultural study. In G. Trommsdorff, W. Friedlmeier, \& H.-J. Kornadt (Eds.), Japan in transition: Social and psychological aspects (pp. 198-211). Lengerich, Germany: Pabst Science.

Trommsdorff, G., \& Friedlmeier, W. (2010). Preschool girls' distress and mothers' sensitivity in Japan and Germany. European Journal of Developmental Psychology, 7, 350-370.

Trommsdorff, G., \& Nauck, B. (2010). Introduction to special section for Journal of CrossCultural Psychology: Value of Children: A concept for better understanding cross- 
PATTERNS OF RELATIONSHIPS

cultural variations in fertility behavior and intergenerational relationships. Journal of Cross-Cultural Psychology, 41, 637-651.

Van de Vijver, F., \& Leung, K. (1997). Methods and data analysis for cross-cultural research. Thousand Oaks, CA: Sage.

Wissink, I. B., Dekovic, M., \& Meijer, A. M. (2006). Parenting behavior, quality of the parent-adolescent relationship, and adolescent functioning in four ethnic groups. The Journal of Early Adolescence, 26, 133-159.

Youniss, J., \& Smollar, J. (1985). Adolescent relations with mothers, fathers, and friends. Chicago: University of Chicago Press. 
Table 1

Descriptions of Measures for German and French Adolescents: Example Items, Means, Standard Deviations, and Internal Consistencies of

Scales

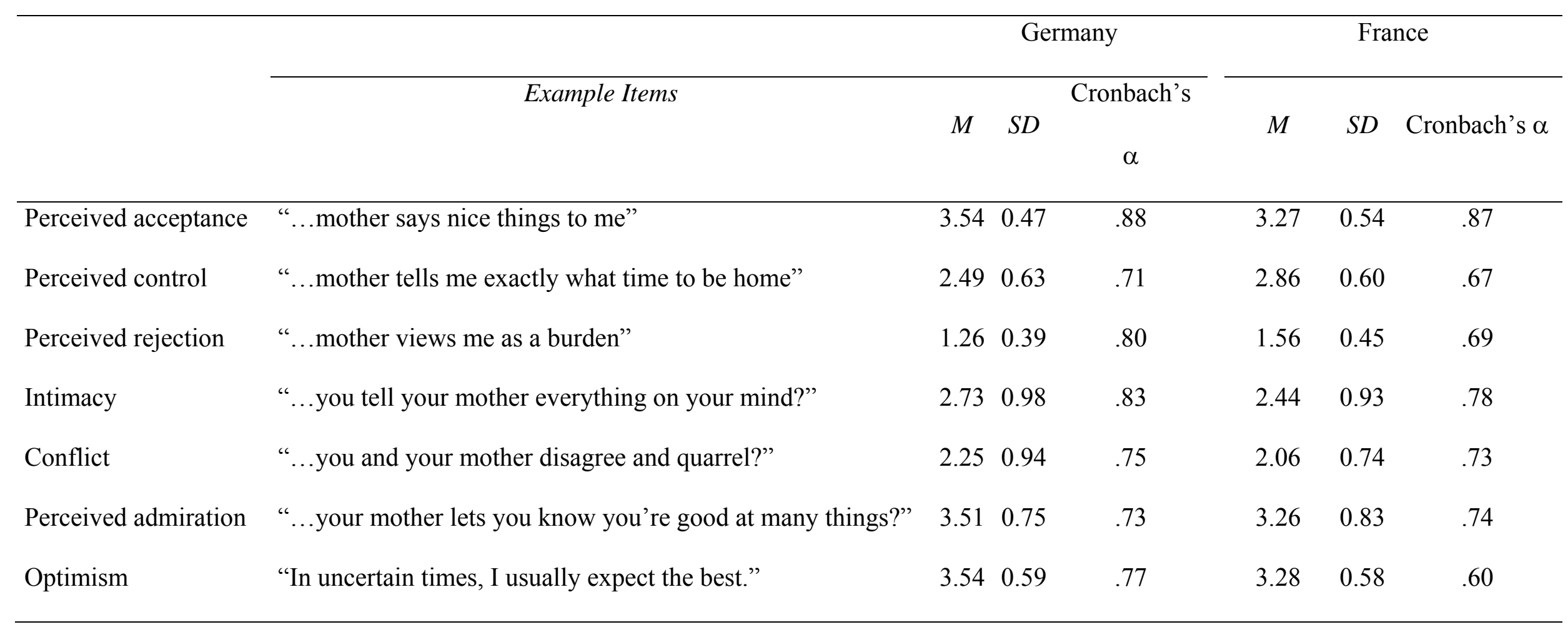


Table 2

Cluster With Respect to Intimacy, Conflict, and Admiration (Nonstandardized Measures)

\begin{tabular}{|c|c|c|c|c|c|c|c|c|}
\hline & \multicolumn{2}{|c|}{$\begin{array}{c}\text { "Secondary" } \\
(n=95)\end{array}$} & \multicolumn{2}{|c|}{$\begin{array}{l}\text { "Tense" } \\
(n=64)\end{array}$} & \multicolumn{2}{|c|}{$\begin{array}{l}\text { "Primary" } \\
(n=91)\end{array}$} & \multicolumn{2}{|c|}{$\begin{array}{c}\text { 'Harmonious' } \\
\quad(n=56)\end{array}$} \\
\hline & $M$ & $S D$ & $M$ & $S D$ & $M$ & $S D$ & $M$ & $S D$ \\
\hline Intimacy & 1.95 & 0.49 & 1.79 & 0.47 & 3.05 & 0.54 & 3.83 & 0.82 \\
\hline Conflict & 1.66 & 0.40 & 3.09 & 0.56 & 2.25 & 0.43 & 1.79 & 0.44 \\
\hline Admiration & 3.08 & 0.64 & 2.74 & 0.64 & 3.54 & 0.48 & 4.38 & 0.54 \\
\hline
\end{tabular}

Note. Reports by adolescents on 5-point scale ( $1=$ never, 5 = always $)$. 
PATTERNS OF RELATIONSHIPS

Table 3

Cross-Table of Cluster Membership and Country

\begin{tabular}{|c|c|c|c|c|c|}
\hline & & \multicolumn{4}{|c|}{ Cluster } \\
\hline & & $\begin{array}{c}\text { "Secondary" } \\
(n=95)\end{array}$ & $\begin{array}{l}\text { "Tense" } \\
(n=64)\end{array}$ & $\begin{array}{l}\text { "Primary" } \\
(n=91)\end{array}$ & $\begin{array}{c}\text { "Harmonious" } \\
(n=56)\end{array}$ \\
\hline \multirow[t]{5}{*}{ Germany } & $N$ observed & 38 & 30 & 54 & 31 \\
\hline & $N$ expected & 47.5 & 32.0 & 45.5 & 28.0 \\
\hline & $\%$ in Germany & 24.8 & 19.6 & 35.3 & 20.3 \\
\hline & $\%$ in the cluster & 40.0 & 46.9 & 59.3 & 55.4 \\
\hline & $\%$ of total sample & 12.4 & 9.8 & 17.6 & 10.1 \\
\hline \multirow[t]{5}{*}{ France } & $N$ observed & 57 & 34 & 37 & 25 \\
\hline & $N$ expected & 47.5 & 32.0 & 45.5 & 28.0 \\
\hline & $\%$ in France & 37.3 & 22.2 & 24.2 & 16.3 \\
\hline & $\%$ in the cluster & 60.0 & 53.1 & 40.7 & 44.6 \\
\hline & $\%$ of total sample & 18.6 & 11.1 & 12.1 & 8.2 \\
\hline
\end{tabular}




\section{PATTERNS OF RELATIONSHIPS}

Table 4

Analyses of Variance Comparing Adolescents in the Four Clusters With Respect to Perceived Parenting and Well-Being in Germany and France
(1) "Secondary"
(2) "Tense"
(3) "Primary"
(4) "Harmonious"

\begin{tabular}{|c|c|c|c|c|c|c|c|c|c|c|c|c|c|c|c|c|c|c|c|c|c|c|}
\hline & \multicolumn{2}{|c|}{ Germany } & \multicolumn{2}{|c|}{ France } & \multicolumn{2}{|c|}{ Germany } & \multicolumn{2}{|c|}{ France } & \multicolumn{2}{|c|}{ Germany } & \multicolumn{2}{|c|}{ France } & \multicolumn{2}{|c|}{ Germany } & \multicolumn{2}{|c|}{ France } & \multicolumn{2}{|c|}{ Country } & \multicolumn{2}{|c|}{ Cluster } & \multicolumn{2}{|c|}{ Country $\times$ Cluster } \\
\hline & $M$ & $S D$ & $M$ & $S D$ & $M$ & $S D$ & $M$ & $S D$ & $M$ & $S D$ & $M$ & $S D$ & $M$ & $S D$ & $M$ & $S D$ & $F$ & $\eta^{2}$ & $F$ & $\eta^{2}$ & $F$ & $\eta^{2}$ \\
\hline $\begin{array}{l}\text { Perceived } \\
\text { acceptance }\end{array}$ & 3.54 & 0.34 & 3.21 & 0.49 & 3.00 & 0.59 & 2.84 & 0.59 & 3.65 & 0.30 & 3.45 & 0.36 & 3.87 & 0.23 & 3.74 & 0.24 & $17.2^{* *}$ & .06 & $48.9^{* *}$ & .33 & 0.85 & .01 \\
\hline $\begin{array}{c}\text { Perceived } \\
\text { control }\end{array}$ & 2.29 & 0.56 & 2.87 & 0.54 & 2.84 & 0.71 & 2.87 & 0.80 & 2.45 & 0.65 & 2.81 & 0.55 & 2.50 & 0.50 & 2.87 & 0.55 & $21.73^{* *}$ & .07 & $2.82^{*}$ & .03 & $2.51^{+}$ & .02 \\
\hline $\begin{array}{l}\text { Perceived } \\
\text { rejection }\end{array}$ & 1.18 & 0.21 & 1.51 & 0.38 & 1.64 & 0.53 & 1.72 & 0.54 & 1.19 & 0.35 & 1.58 & 0.46 & 1.13 & 0.15 & 1.40 & 0.37 & $33.36^{* *}$ & .10 & $13.64^{* *}$ & .12 & $2.17^{+}$ & .02 \\
\hline Optimism & 3.54 & 0.50 & 3.20 & 0.51 & 3.34 & 0.59 & 3.15 & 0.72 & 3.57 & 0.57 & 3.38 & 0.59 & 3.72 & 0.64 & 3.46 & 0.48 & $12.67^{* *}$ & .04 & $4.24 * *$ & .04 & 0.30 & .00 \\
\hline
\end{tabular}


PATTERNS OF RELATIONSHIPS

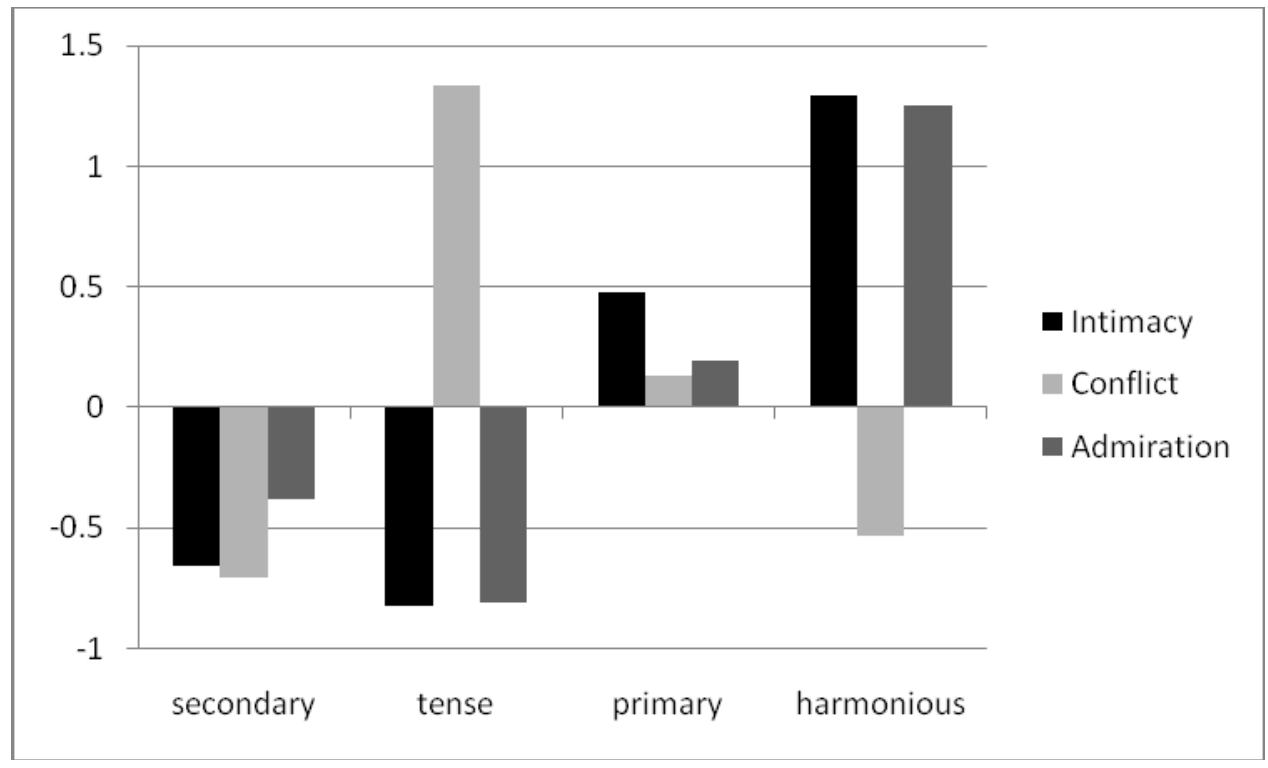

Figure 1. Clusters with respect to intimacy, conflict, and perceived admiration (standardized measures). 